Article

\title{
Limitations of Urban Infrastructure for the Large-Scale Implementation of Electric Mobility. A Case Study
}

\author{
José Ángel López-Sánchez ${ }^{1}$, Francisco Javier Garrido-Jiménez ${ }^{2} \mathbb{D}$, Jose Luis Torres-Moreno ${ }^{1, * \mathbb{C}}$, \\ Alfredo Chofre-García ${ }^{3}$ and Antonio Gimenez-Fernandez ${ }^{1}$ (D) \\ 1 Department of Engineering, University of Almeria, 04120 Almeria, Spain; ja.lopezs88@gmail.com (J.A.L.-S.); \\ agimfer@ual.es (A.G.-F.) \\ 2 Department of Engineering, University of Almeria, Planning Board. 3, Marin Sq, 04003 Almeria, Spain; \\ fjgarrido@aytoalmeria.es \\ 3 E-distribución, 130 Almeria Rd, Huercal de Almeria, 04130 Almeria, Spain; alfredo.chofre@enel.com \\ * Correspondence: jltmoreno@ual.es
}

Received: 14 April 2020; Accepted: 18 May 2020; Published: 22 May 2020

\begin{abstract}
The large-scale implementation of electric vehicles involves many challenges, including the stress on electric distribution networks. In order to quantify this impact, an input-output methodology applied to a case study in a representative urban context is proposed. The analysis shows that, on average, a standard distribution network can withstand $40 \%$ electric vehicle penetration without an increase in its capacity, always in the case of slow night charging. Higher levels of penetration are difficult to obtain without electric grid reinforcements because both lower energy prices and usual transport habits create a strong peak power demand during the night. The study also confirms that semi-fast or fast charging systems are not acceptable as domestic technologies due to the lack of capacity in transformation centers and their unsuitability for standard low voltage lines.
\end{abstract}

Keywords: urban infrastructure; electric vehicle; electric distribution network

\section{Introduction}

The reduction of air pollution is a global priority due to its impact on human health, climate change, and the destruction of the ozone layer. Although it is difficult to quantify the number of victims of air pollution, according to the World Health Organization (WHO), in 2004, premature deaths from particles resulting from air pollution exceeded $1 \%$ of the total [1]. Currently, researchers are working to establish the more precise impacts of air pollution on human health. Some studies indicate that its effects are beginning to spread beyond large cities [2,3].

Transport in its different modes contributes to $27 \%$ of the total greenhouse gas (GHG) emissions, among which $72.9 \%$ comes from road transport [4]. This percentage is even higher for cities [5]. In the specific case of Almeria (the municipality object of the current case study), the Sustainable Urban Mobility Plan shows that $40 \%$ of trips within the municipality are made by private vehicles, of which almost $99 \%$ are powered by internal combustion engines (ICEs). The consequences of the large-scale use of these fuels are well known. The emissions of particulates, and GHG and noise pollution are the economic and strategic focus of non-producing countries. In this context, the promotion of electric vehicles (EVs), accompanied by an increase in the use of renewable energy via electricity generation, might offer a solution to these shortcomings.

However, the large-scale penetration of EVs may exert stress on both the transport and electric distribution networks. In the case of urban distribution networks, whose capacity is intrinsically 
difficult to increase due to a lack of vacant space, this problem is more serious. In addition, since the potential users of EVs prefer home charging [6], it is crucial to determine whether current urban infrastructures are ready for large-scale EV penetration.

The aim of this article is to answer this question by analyzing the impact of large-scale EV penetration on a standard electric distribution network through a case study. We also propose a methodology based on the demand, estimated using fiscal databases and an assessment of the supply capacity through real data provided by the electric grid operator. The results obtained should be applicable to other similar socio-economic situations, while the methodology can be used in a broader range of urban contexts.

The article is structured as follows. Section 2 provides a summary of the state-of-the-art of electric mobility, ranging from the different types of vehicles and their charging modes to the procedures used for studying their impacts at the infrastructure level. In Section 3, the methodology used in the study and the origin of the data are presented. The fourth section presents the results, which is followed by a discussion of the findings in Section 5. Finally, the main conclusions of the research are highlighted.

\section{Background}

There is an increasing need to implement EVs on a larger scale. For this reason, several studies have tried to forecast their implantation possibilities based on different scenarios and public policies $[7,8]$. One of the main barriers to EV penetration lies in the well-known "chicken and egg paradigm". For more charging stations to exist, those stations must be profitable, which is difficult while the demand remains low [8]. However, because there are few charging stations, people are reluctant to buy an EV. In addition, potential customers prefer to use cheaper home-charging systems [9]. For a better understanding of the subject, it is necessary to briefly describe the roles of the stakeholders involved in the penetration of EVs, the current stage of the technology at both the vehicle and infrastructure levels, and the techniques being used to facilitate EV studies.

\subsection{Stakeholders}

Three stakeholders can be distinguished in the issue of EV penetration: potential customers, public administrations, and private companies. (i) Potential clients: this category includes "early adopters", including those who are environmentally conscious and those who see EVs as a form of investment by reducing their total vehicle ownership costs (TOCs). Another group includes "performance seekers", who see EVs as a more avant-garde technology than conventional vehicles. The third group is composed of "late-adopters", who follow trends and determine vehicle reliability based on the experiences of other drivers. Finally, there are those who are reluctant to change or are unaware of environmental considerations and the advantages that EVs have over ICE vehicles. (ii) Authorities: at the national level, governments can establish global strategies in favor of the implementation of EVs, thereby promoting incentives for their acquisition or the use of renewable energy. These types of measures are usually harmonized through international treaties [7]. At the local level, municipalities play a very important role in both the regulation of atmospheric and noise pollution and in the regulation and supervision of the charging infrastructure, especially for stations located in public roads. Since the time necessary for an electric vehicle to recharge is much longer than that for an ICE vehicle, the space needed for a future EV pool could increase the problem of parking in cities, an aspect that should be properly managed. These authorities can also provide tax incentives for the acquisition of EVs by reducing road taxes. In addition, municipalities may manage municipal utilities to provide public services such as electricity supply, the operation of distribution systems, the management of parking lots in garages and public spaces, and public transport. (iii) Companies: this category includes electricity distributors and suppliers, the manufacturers of charging systems, the installers of charging infrastructure, vehicle manufacturers, passenger transport companies, private parking operators, and gas stations.

Apart from the traditional relationships between these stakeholders, new relationships must be established between the electricity and the transport sectors (i.e., the local authorities), who have already 
been working with both agents in a privileged position, to guarantee proper coordination. Potential customers experience barriers to the rapid growth of EVs, such as costs (if they do not receive incentives), the availability of information, poor autonomy, technological uncertainty (generally due to batteries), the current strength of the ICE vehicle industry, and, above all, the charging infrastructure $[10,11]$.

\subsection{The Current State of Electric Vehicle Technology}

EVs can be classified into hybrid electric vehicles (HEVs) and fully electric vehicles (FEVs). HEVs, which can be pluggable or not, have a series configuration (also known as extended-range) in which the combustion engine, which works at its optimal point to charge the batteries, is not coupled to the propulsion system, and a parallel configuration, where the combustion engine is connected to the propulsion system [12]. HEVs have the advantage of greater autonomy, even though they have certain drawbacks, such as GHG emissions and more complex mechanics. FEVs do not emit GHGs and have simpler mechanics since they neither incorporate an internal combustion engine nor the elements associated with it. In addition, they have no access restrictions to low emission areas [12]. Conversely, they have the disadvantage of low autonomy. However, research is enabling the improvement of batteries and the search for new ways to use them, such as leasing [13]. There are other types of electric vehicles, such as fuel cell vehicles, but their high cost and premature state of technological development indicate less penetration than the types mentioned above [14].

As indicated above, one of the key aspects that might condition the degree of $\mathrm{EV}$ penetration in the following years is the sum of their acquisition and maintenance costs compared to traditional ICE vehicles. For this reason, we apply the concept of TOCs, which allows for a comparison of both alternatives from a purely economic point of view. This criterion takes into account aspects such as (i) energy consumption, which is considerably lower for EVs; (ii) maintenance costs, which are usually lower for EVs [14]; (iii) the rental costs of the battery, in the case of a leasing regime; (iv) the costs of periodic inspections, which are lower for EVs because exhaust gases do not have to be measured; and (v) taxes, which are usually lower for EVs. Considering all the previous variables, a study can be designed based on the profitability of EVs for a given time horizon and mileage, which can also be used to design public incentives for the acquisition of such vehicles.

Another aspect that could determine the level of EV penetration is the speed and method of the battery charging process. Considering charging speed, in Spain there are three charging technologies [13]. In the first, called slow charging, the EV is charged using a $230 \mathrm{~V}$ single-phase alternating current at maximum intensity of $16 \mathrm{~A}$. The second is called semi-fast charging and can use both single-phase and three-phase alternating current, reaching up to $63 \mathrm{~A}$ intensities. The third and last type of charging, called fast charging, is carried out using direct current at voltages of up to $500 \mathrm{~V}$ and intensities ranging from 5 to $550 \mathrm{~A}$. The average duration of slow charging ranges between 6 and $8 \mathrm{~h}$, while semi-fast charging can be completed in less than two hours and fast charging from 5 to $30 \mathrm{~min}$ [15]. The different durations of these three charging systems result in very different peak power demand, which is a paramount aspect from the perspective of the electric network capacity. Another important aspect that affects the charging infrastructure is that there is currently no standard in Spain for connectors and the rest of the elements involved [13]. Thus, in slow charging, the EV is connected to a domestic installation using a standard $16 \mathrm{~A}$ cable. In the semi-fast charging mode, when the vehicle is connected to the network using standard plugs of up to 32 A per phase, electronic units in charge of verifying the correct state of certain parameters during charging are usually incorporated. In fast charging, the EV is connected to the electric network via external equipment. In Spain, fast charging is the mode with the greatest presence in public charging stations. Finally, there are three fundamental ways to manage charging. In the dumb load mode, users are allowed to charge their vehicles indiscriminately, as if they were just another load at home. This absence of management produces what is known as the "worst case scenario" since the charging process is usually carried out after the last use of the car at the end of the day, thereby inducing high simultaneity with other users. To avoid this situation, there are two different management modes: time discrimination 
and smart charging. Time discrimination is based on agreements between the electrical operators and users ensuring that a part of the charging takes place during off-peak hours. This allows users to save money and the electric grid operators to optimize their infrastructure. Smart charging is a step forward for time discrimination, with more sophisticated management due to the use of real-time information on the power demands of the electric network. This charging management system is usually integrated into so-called smart grids that use control algorithms to optimize the efficiency of all elements that comprise the electric system and may include micro generators. In this type of network, the level of EV penetration plays a key role, with the network able to act as a regulatory agent through what is known as vehicle-to-grid (V2G) technology [16].

\subsection{Previous Research on the Impact of the Electric Vehicle on the Electric Network}

To evaluate the impact of a significant penetration of EVs on an electric network, it is necessary to analyze both the energy demands and the infrastructure offered in different scenarios. Thus, for demand, the vehicle pool should be characterized together with vehicles' current patterns of use. For example, the electric network scope, topology, capacity, and resilience must be assessed through parameters such as the medium voltage to low voltage (MV/LV) transformers load, voltage drops, phase balancing, or thermal limitations [17-25]. By comparing the two factors, the authors of [26] compared the impacts of different scenarios of EV penetration in five European countries. The increase in the energy peak of demand in Spain would be $0.45 \%, 0.90 \%$, and $2.3 \%$ for realistic, aggressive, and very aggressive scenarios of penetration and dumb management. These percentages would place Spain in third place behind the United Kingdom and Germany. In order to assess the demand increase, vehicles were divided into categories, and a specific average consumption value was proposed to define the energy consumption ratio for each kilometer travelled. This procedure was also used in [27]. In [28], this classification was reduced to three types of vehicles that charge at $1.5 \mathrm{~kW}, 3 \mathrm{~kW}$, and $6 \mathrm{~kW}$ power peaks, respectively, assuming an equal daily distance travelled for each category, with two specific consumption levels, and a four-hour charging time. According to the simulations, the EV penetration level for dumb management could reach $10 \%$, while that under a smart charging system could reach $52 \%$. The key to these increases in the level of penetration lies in the ability to implement management strategies in real time [29]. Most of these studies used the commercial PSSE software to carry out electric network simulations, although ad-hoc tools, such as those found in [30], were also applied. In [31], a reinforcement percentage between $10 \%$ and $15 \%$ was estimated for the MV/LV grid under a scenario with a high EV penetration level. With transformer substations, this percentage could exceed $30 \%$. Each of these reinforcements might involve a cost of $€ 400$ for each vehicle. Regarding the estimation of demand, most previous research has used simulations based on stochastic models to predict the increase in energy demand under different levels of EV penetration. However, estimation models based on machine learning [32] and the application of big data techniques from empirically obtained information [33] have also been developed, as well as those based on information from the real-time locations of users while they remain in their charging stations [34].

\section{Materials and Methods}

The aim of this study was to determine whether a conventional electric distribution network can support the increase in demand resulting from a complete transformation of an urban settlement's vehicle pool from ICE vehicles to EVs. Instead of using a typical macro or statistical analysis [35-39], this research was carried out using an input-output study at a micro level, based on the exhaustive estimation of potential EV demands and the capacity of the electric distribution network in a standard urban settlement-in this case, La Cañada de San Urbano (Almeria, Spain), with a population of about 6000 inhabitants (2019). This village was chosen due to several considerations. Firstly, it has a historical population with complex internal patterns, both from a morphological (an average housing density of $45 \mathrm{dw} /$ ha with a mixture of multi-family and single-family buildings) and socio-economic (a mixture of residential, commercial, and industrial activities) perspective. Its global motorization rate (although 
in this study, only passenger cars were considered) is around 550 vehicles per 1000 inhabitants based on the Spanish average. In addition, according to the electricity operator, the curve of electricity demand is similar to that of the Spanish standard. Secondly, from a practical point of view, this city has well-defined physical limits that allow for the accurate characterization of both its vehicle pool and the electric network that would serve it.

The data necessary to characterize La Cañada de San Urbano's electric network were supplied by the exclusive grid operator, in this case, from the company called e-distribución, according to the 24/2013 Electric Spanish Law. To carry out this study, only the power available in the MV/LV transformers $(20 \mathrm{kV} / 400 \mathrm{~V})$ and the area supplied by each transformer were considered. The distribution of the loads among the different low voltage (LV) lines was not taken into account. This simplification is admissible since both the modification of the topology and the reinforcement of LV lines across a public space is relatively simple as long as there is vacant power in the ML/LV transformers. However, building or expanding transformers in dense urban areas is much more complicated. The area's infrastructure is accordingly represented by the MV/LV transformers with their location, power, and range of action, which is understood as the maximum envelopment (with small adjustments) of the associated LV lines. A representation of the electric infrastructure in La Cañada de San Urbano is shown in Figure 1.

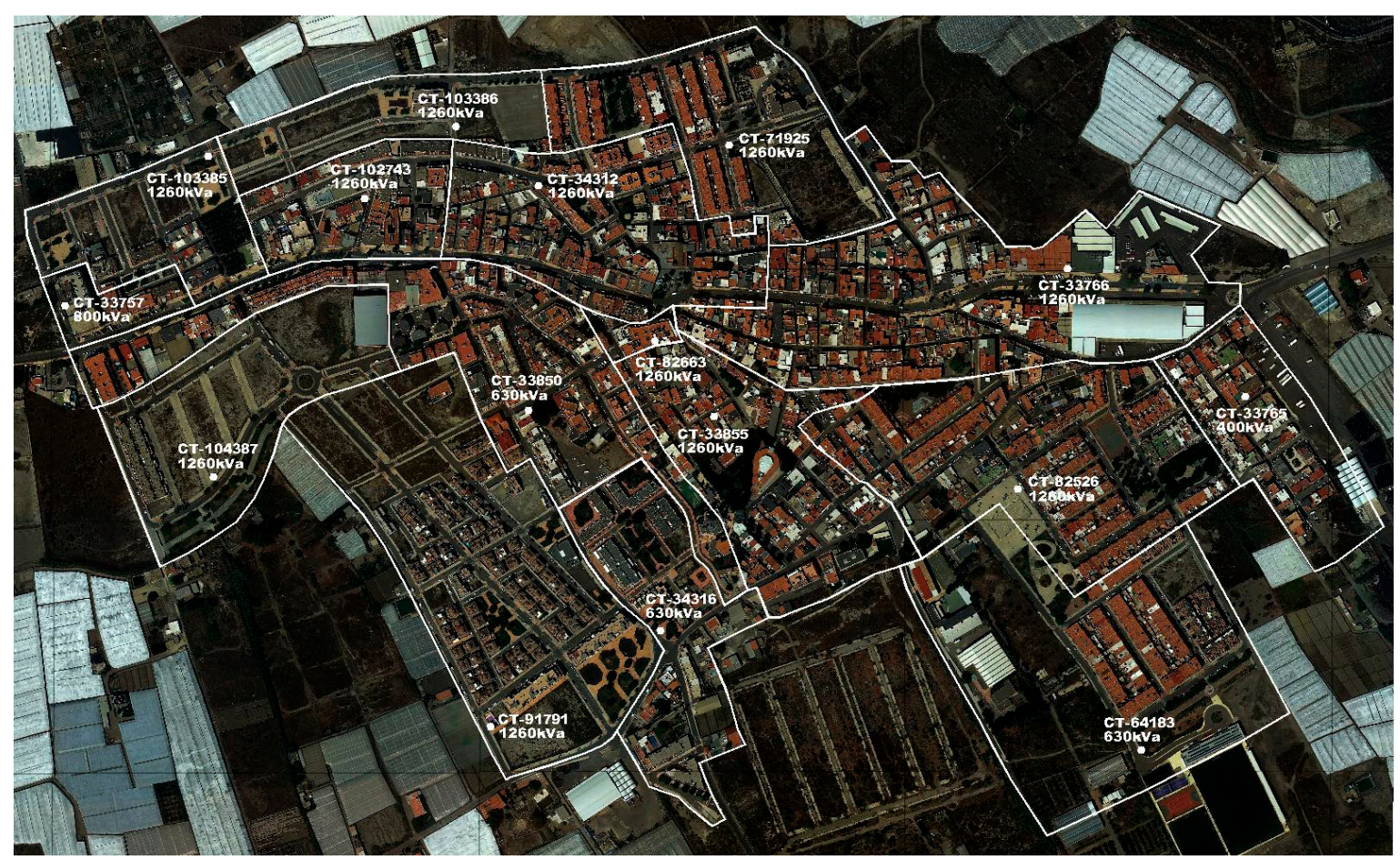

Figure 1. La Cañada de San Urbano's electric network.

Obviously, not all the MV/LV transformers' power was available since the demand from electric mobility must be added to pre-existing loads. As indicated, according to the data provided by e- distribución, the demand curve in La Cañada de San Urbano does not differ from the Spanish standard, which is represented in Figure $2[40,41]$. 


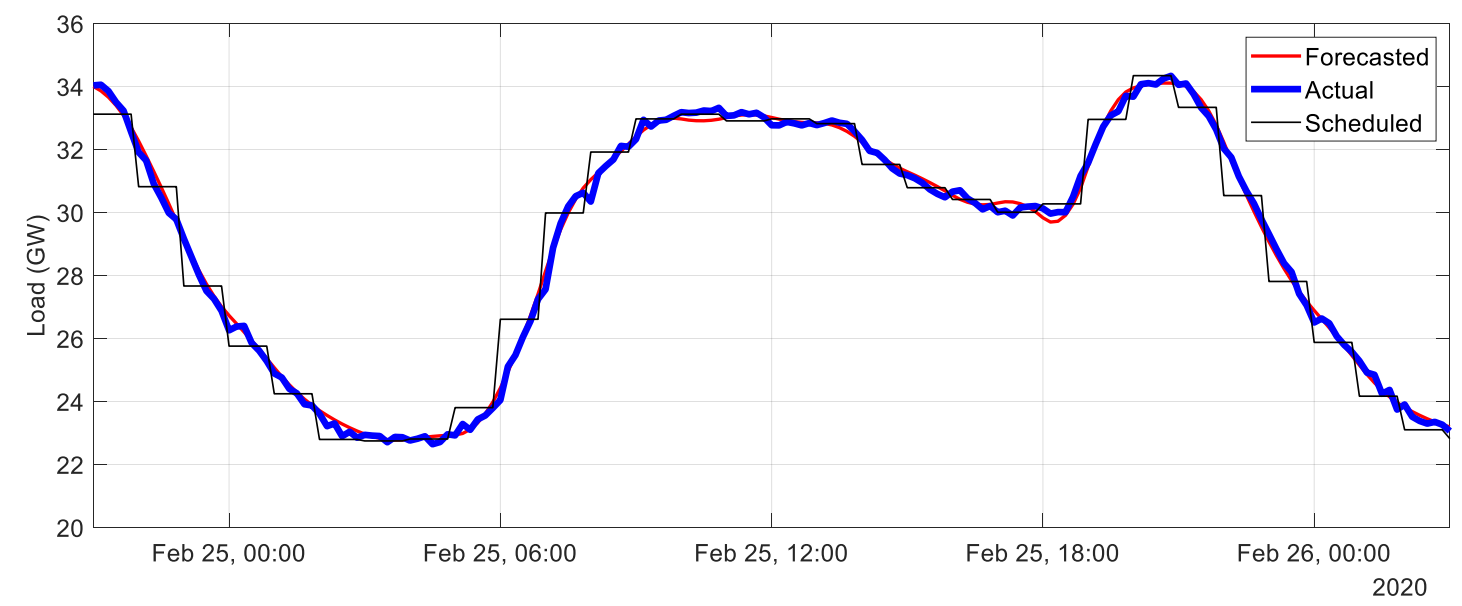

Figure 2. The standard Spanish curve of electrical demand. Data for an average day (25 February 2020) obtained from the authors of [40].

Taking into account the aforementioned factors, we assumed that the three charging modes (slow, semi-fast, and fast) were applied during the night period. This agrees not only with the electric grid's capacity but also with the habits of the citizens and electricity pricing (see Appendix B). Thus, comparing the maximum daily demand shown in Figure $2(34 \mathrm{GW})$ with the maximum load during the $0-8 \mathrm{~h}$ period (around $27 \mathrm{GW}$ ), it was possible to deduce that at least $21 \%$ of the power in the MV/LV transformers should always be available to perform slow charging during the night. Doing the same operation for semi-fast ( $3 \mathrm{~h}$ duration) and fast (30 $\mathrm{min}$ ) charging, the minimum vacant power with respect to the daily maximum would be $30 \%$ (24 GW vs $34 \mathrm{GW}$ between 3:00 and 6:00 a.m.). In all three situations, the MV/LV transformers' overcapacity above the maximum daily load could be added, but this factor was not considered in this study in order to avoid biases resulting from unique situations.

For demand, we considered a scenario where $100 \%$ of passenger cars become EVs simultaneously while maintaining their ICE-equivalent characteristics. In the case of trucks and buses, conventional ICE traction was maintained since there are no equivalent $\mathrm{EVs}$ on the market. Starting from this foundation, to forecast the total energy demand, it was necessary to carry out two operations: (i) characterize the current pool of vehicles in La Cañada de San Urbano; and (ii) convert that pool of vehicles to equivalent electric models. The source used to estimate the number and characteristics of the vehicles was the City of Almeria Vehicle Census (the administrative municipality of La Cañada de San Urbano). This census, which was elaborated for fiscal purposes (Mechanical Traction Vehicle Tax), was especially suitable for this study since it provided data not only on the number of vehicles but also about their fiscal power and address, which allowed us to assign each vehicle to a specific MV/LV transformer. The fiscal power was converted to real engine power following the methodology indicated in the 2822/1998 Spanish Vehicle Regulations. The expression applicable to electric engines is as follows:

$$
\text { Fiscal Power }(\mathrm{FHP})=\text { Electric Engine Power }(\mathrm{HP}) / 5.152
$$

The equivalence of each fiscal power range with its equivalent EV model is shown in Table 1. The models were chosen from among those with the ghest number of sales. 
Table 1. Electric and conventional vehicle equivalences [42].

\begin{tabular}{|c|c|c|c|c|c|c|}
\hline $\begin{array}{l}\text { Fiscal Power } \\
\text { Range (FHP) }\end{array}$ & $\begin{array}{l}\text { Electric } \\
\text { Model }\end{array}$ & $\begin{array}{l}\text { Power } \\
(\mathrm{kW})\end{array}$ & $\begin{array}{l}\text { Model Fiscal } \\
\text { Power (FHP) }\end{array}$ & $\begin{array}{l}\text { Battery } \\
\text { (kWh) }\end{array}$ & $\begin{array}{c}\text { Range } \\
(\mathbf{k m})\end{array}$ & $\begin{array}{c}\text { Energy Comp. } \\
(\mathbf{k W h} / \mathbf{k m})\end{array}$ \\
\hline$<8$ & $\begin{array}{l}\text { Renault } \\
\text { Twizy }\end{array}$ & 4 & 0.78 & 6.1 & 100 & 0.06 \\
\hline 8-11.99 & $\begin{array}{l}\text { Citroën } \\
\text { C-Zero }\end{array}$ & 49 & 9.51 & 15.2 & 150 & 0.10 \\
\hline $12-15.99$ & Nissan Leaf & 80 & 15.53 & 24 & 200 & 0.12 \\
\hline 16-19.99 & Volks. eGolf & 100 & 19.41 & 35.8 & 300 & 0.12 \\
\hline$>20$ & Tesla Model 3 & 379 & 73.56 & 80.5 & 530 & 0.15 \\
\hline
\end{tabular}

It should be noted that the range of all vehicles was greater than the average daily distance statistically travelled by each vehicle, which ranged between approximately 46 and $65 \mathrm{~km}$ [43-45].

Once the energy demand was known, to calculate the maximum peak power stressing the electric grid, it was necessary to estimate the load's simultaneity coefficient [46], which was representative of the maximum percentage of vehicles connected to the electric network simultaneously. From this perspective, we analyzed two extreme situations: i) the most unfavorable for the electric grid, where all the vehicles are charging simultaneously during the same night; and 2) the most favorable, where the loads are spaced as much as possible according the capacity of their batteries and average mileage. To consider both factors, an average mileage of $55 \mathrm{~km}$ per day was considered (Table 2).

Table 2. Maximum interval between charges.

\begin{tabular}{ccc}
\hline Electric Model & Battery Range (km) & Interval Between Charging (days) \\
\hline Renault Twizy & 100 & 1.81 \\
Citroën C-Zero & 150 & 2.72 \\
Nissan Leaf & 200 & 3.63 \\
Volks. eGolf & 300 & 5.45 \\
Tesla Model 3 & 530 & 9.63 \\
\hline
\end{tabular}

Once both the electric network possibilities and the energy demand resulting from the vehicle pool conversion were estimated, the viability of large-scale EV penetration was determined by taking into account the different peak power demands of each charging technology (i.e., slow, semi-fast, and fast).

\section{Results}

\subsection{Global Data}

A comparison between the power available in each MV/LV transformer and the potential demand from the conversion to EVs for all of Cañada de San Urbano's passenger vehicles is shown in Table 3. For clarification purposes, the simultaneous aggregate energy demand and each charging technology power demand are reflected without considering the average daily mileage or a coefficient of simultaneity that diminishes the demand. A value of $\cos \varphi=0.85$ was applied to convert the value from $\mathrm{kVA}$ to $\mathrm{kW}$. The disaggregated data for the number of vehicles in each category assigned to each $\mathrm{MV} / \mathrm{LV}$ transformer are shown in Appendix A.

Table 3 represents the worst-case scenario from the perspective of the electricity network, where all vehicles are charged simultaneously during the same night. The opposite case would involve considering the relationship between the capacity of the batteries and the daily mileage (Table 2). In this situation, the maximum time gap between charging was obtained, which operated in practice as a coefficient of simultaneity for the energy and power demand. In this way, the obtained results reflect the minimum demand hypothesis (Table 4). 
Table 3. Maximum power offered and demanded in each MV/LV transformer.

\begin{tabular}{|c|c|c|c|c|c|c|c|}
\hline $\begin{array}{l}\text { MV/LV } \\
\text { Transfer } \\
\text { Number }\end{array}$ & $\begin{array}{c}\text { Power Installed } \\
\text { (kVA) }\end{array}$ & $\begin{array}{c}\text { Max. Power } \\
\text { Available } \\
\text { Slow Charge } \\
(\mathbf{k W})\end{array}$ & $\begin{array}{c}\text { Max. Power } \\
\text { Available } \\
\text { Fast Charge } \\
\text { (kW) }\end{array}$ & $\begin{array}{l}\text { Max. Daily } \\
\text { Energy } \\
\text { Demand } \\
(\mathrm{kWh})\end{array}$ & $\begin{array}{c}\text { Max. Power } \\
\text { Demand } \\
\text { Slow Charge } \\
(\mathrm{kW})\end{array}$ & $\begin{array}{l}\text { Max. Power } \\
\text { Demand } \\
\text { Semi-Fast } \\
\text { Charge (kW) }\end{array}$ & $\begin{array}{c}\text { Max. Power } \\
\text { Demand } \\
\text { Fast Charge } \\
(\mathrm{kW})\end{array}$ \\
\hline 103.385 & 1260 & 225 & 321 & 2655 & 332 & 885 & 5310 \\
\hline 33.757 & 800 & 143 & 204 & 1672 & 209 & 557 & 3344 \\
\hline 102.743 & 1260 & 225 & 321 & 208 & 26 & 69 & 416 \\
\hline 103.386 & 1260 & 225 & 321 & 24 & 3 & 8 & 48 \\
\hline 34.312 & 1260 & 225 & 321 & 6165 & 771 & 2055 & 12.331 \\
\hline 71.925 & 1260 & 225 & 321 & 1699 & 212 & 566 & 3398 \\
\hline 33.766 & 1260 & 225 & 321 & 4404 & 551 & 1468 & 8809 \\
\hline 104.387 & 1260 & 225 & 321 & 40 & 5 & 13 & 78 \\
\hline 33.850 & 630 & 113 & 160 & 3715 & 464 & 1239 & 7432 \\
\hline 82.663 & 1260 & 225 & 321 & 63 & 8 & 21 & 126 \\
\hline 33.855 & 1260 & 225 & 321 & 9029 & 1129 & 3010 & 18.059 \\
\hline 82.526 & 1260 & 225 & 321 & 6825 & 853 & 2275 & 13.651 \\
\hline 33.765 & 400 & 72 & 102 & 2650 & 331 & 884 & 5301 \\
\hline 64.183 & 630 & 113 & 160 & 2388 & 298 & 796 & 4776 \\
\hline 91.791 & 1260 & 225 & 321 & 924 & 116 & 308 & 1849 \\
\hline 34.316 & 630 & 113 & 160 & 1498 & 187 & 499 & 2997 \\
\hline AVER. & 1060 & 189 & 270 & 2747 & 343 & 916 & 5495 \\
\hline
\end{tabular}

Table 4. Minimum power offered and demanded in each MV/LV transformer.

\begin{tabular}{|c|c|c|c|c|c|c|c|}
\hline $\begin{array}{l}\text { MV/LV } \\
\text { Transfer } \\
\text { Number }\end{array}$ & $\begin{array}{c}\text { Power Installed } \\
\text { (kVA) }\end{array}$ & $\begin{array}{c}\text { Max. Power } \\
\text { Available } \\
\text { Slow Charge } \\
\text { (kW) }\end{array}$ & $\begin{array}{c}\text { Max. Power } \\
\text { Available } \\
\text { Fast Charge } \\
(\mathrm{kW})\end{array}$ & $\begin{array}{l}\text { Max. Daily } \\
\text { Energy } \\
\text { Demand } \\
\text { (kWh) }\end{array}$ & $\begin{array}{l}\text { Max. Power } \\
\text { Demand } \\
\text { Slow Charge } \\
(\mathrm{kW})\end{array}$ & $\begin{array}{l}\text { Max. Power } \\
\text { Demand } \\
\text { Semi-Fast } \\
\text { Charge (kW) }\end{array}$ & $\begin{array}{l}\text { Max. Power } \\
\text { Demand } \\
\text { Fast Charge } \\
(\mathbf{k W})\end{array}$ \\
\hline 103.385 & 1260 & 225 & 321 & 816 & 102 & 272 & 1633 \\
\hline 33.757 & 800 & 143 & 204 & 502 & 63 & 167 & 1004 \\
\hline 102.743 & 1260 & 225 & 321 & 62 & 8 & 21 & 124 \\
\hline 103.386 & 1260 & 225 & 321 & 7 & 1 & 2 & 13 \\
\hline 34.312 & 1260 & 225 & 321 & 1880 & 235 & 627 & 3760 \\
\hline 71.925 & 1260 & 225 & 321 & 507 & 63 & 169 & 1015 \\
\hline 33.766 & 1260 & 225 & 321 & 1334 & 167 & 445 & 2668 \\
\hline 104.387 & 1260 & 225 & 321 & 12 & 2 & 4 & 25 \\
\hline 33.850 & 630 & 113 & 160 & 1130 & 141 & 377 & 2259 \\
\hline 82.663 & 1260 & 225 & 321 & 19 & 2 & 6 & 38 \\
\hline 33.855 & 1260 & 225 & 321 & 2722 & 340 & 907 & 5443 \\
\hline 82.526 & 1260 & 225 & 321 & 2047 & 256 & 682 & 4095 \\
\hline 33.765 & 400 & 72 & 102 & 772 & 97 & 257 & 1545 \\
\hline 64.183 & 630 & 113 & 160 & 737 & 92 & 246 & 1473 \\
\hline 91.791 & 1260 & 225 & 321 & 269 & 34 & 90 & 539 \\
\hline 34.316 & 630 & 113 & 160 & 465 & 58 & 155 & 930 \\
\hline AVER. & 1060 & 189 & 270 & 830 & 104 & 277 & 1660 \\
\hline
\end{tabular}

Based on a comparison between the results of Tables 3 and 4, the minimum energy (and power) demand would be $30.3 \%$ of the maximum, which represents a coefficient of simultaneity of $0.303(0.3)$ compared to the worst-case scenario. This is an interesting result because it determines the level at which demand would move under any hypothesis.

However, the average values reflected in Tables 3 and 4 must be analyzed with caution. Transformers No. 103.386 and No. 104.387 MV/LV experience minimal loads because they are intended to supply new urban developments, which are currently mostly unbuilt. Transformer No. 91.791 is partially in the same situation. Transformer No. 82.663 can be considered a singularity within the electric grid due to its low range of LV lines. These singularities have been considered in the analysis of the three charging hypotheses presented below.

\subsection{Slow Charging Hypothesis}

The analysis in Table 3 shows that, in the event of the simultaneous slow charging of all vehicles during a given night (and excluding the four MV/LV transformers with singularities), only two transformers would be able to supply the new load. By eliminating these MV/LV transformers with singularities, the average power demand would increase from $343 \mathrm{~kW}$ to $447 \mathrm{~kW}$, a power that is much higher than the average available in the transformers, which is around $177 \mathrm{~kW}$ at 0:00 and 8:00 a.m. (once the same correction has been made). This hypothesis of a fully concurrent load, although unlikely, 
is not impossible and must be analyzed to show the maximum stress that the electrical system could face under full penetration of slow or dumb charging technology.

Under a maximum time gap between EV charging sessions (Table 4) (a highly improbable hypothesis that represents the minimum demand for the electric distribution network), and ignoring the four MV/LV transformers with singularities, seven transformers would have the capacity to supply the night-time demand. In this case, the average demand $(135 \mathrm{~kW})$ would be below the capacity available in the transformers $(177 \mathrm{~kW})$.

These two extreme hypotheses indicate that, for slow charging, the average power offer $(177 \mathrm{~kW})$ would equal the average power demand under a simultaneity coefficient of $0.396(0.4)$ for the simultaneous charging hypothesis. This can be observed in Figure 3.

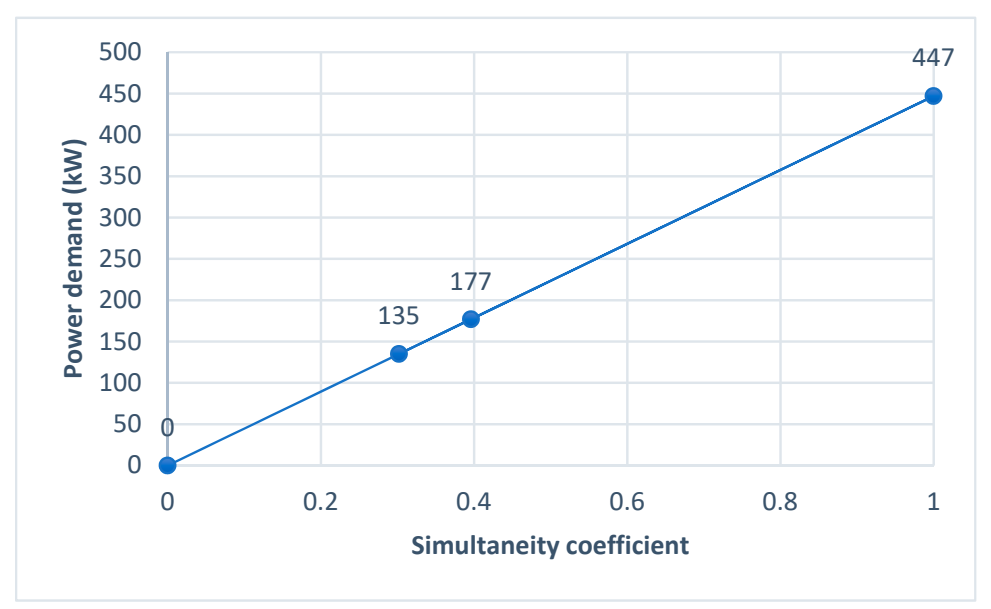

Figure 3. Power demand for different simultaneity coefficients: slow charging.

Although, as indicated, the limitations derived from the particularities of the LV lines were not considered, the MV/LV standard transformer's power is usually divided into $8 \mathrm{LV}$ lines, each one composed of $3 \times 240 / 150 \mathrm{~mm}^{2} \mathrm{Al}$ protected with $160 \mathrm{~A}$ fuses and featuring a capacity around $150 \mathrm{~kW}$. Since the average slow charging load for each LV line ranges between $17 \mathrm{~kW}$ and $56 \mathrm{~kW}$, in the case of simultaneity coefficients over 0.57 , the LV lines should be reinforced. Nevertheless, since a standard $\mathrm{MV} / \mathrm{LV}$ transformer can be electrically amplified to as many as $16 \mathrm{LV}$ lines, the LV network is not a critical potential issue in the implementation of this charging system.

\subsection{Semi-Fast Charging Hypothesis}

In the case of semi-fast charging under the hypothesis of complete simultaneity, only one $\mathrm{MV} / \mathrm{LV}$ transformer would be able to supply the increase in power demand. Moreover, the average power demand $(1192 \mathrm{~kW})$ would far exceed the average capacity during the most favorable period (3:00-6:00 a.m.), which is around $253 \mathrm{~kW}$. In the least-demand hypothesis, logically, the demand would fall and approach the MV/LV transformers' capacity, five of which would have enough capacity to cover the demand increase. However, the average demand, $360 \mathrm{~kW}$, would remain $42 \%$ over the vacant capacity.

\subsection{Fast Charging Hypothesis}

Although the short duration of this type of charging, which has been estimated at $30 \mathrm{~min}$, might lead to lower simultaneity coefficients than the previous situations, the daily average power demand in the most favorable case (concurrence of the minimum number of vehicles charging during the same night) is more than 8.50 times the average offer. Thus, even with a staggered charge during the complete interval between 0:00 am and 8:00 a.m., it is unlikely that this charging technology could be implemented without reasonable uncertainty from a theoretical perspective. 


\section{Discussion}

As shown, the use of real data to estimate the capacity of the electric distribution network and the fiscal census to characterize the vehicle pool composition was especially effective since it allowed for an individualized analysis of the three charging alternatives under two different hypotheses. Thus, this case study provided results that can be extrapolated to similar urban contexts, while the methodology itself has been explained in detail to facilitate its use in different geographical or socio-economic situations.

From the results obtained, it can be deduced that the complete transformation of the ICE vehicle pool into equivalent EVs using a slow charge system during the night would be theoretically feasible without special reinforcements in the electric distribution network (at least at the MV/LV transformers level) under certain conditions. These conditions would depend on the consecution of a load coefficient of simultaneity around 0.4 , which could be somewhat higher if the MV/LV transformers overcapacity is considered. However, this value is not realistic since the simultaneity coefficients for the LV loads supplied from the same transformer are not usually below 0.7 [47] and can even reach values above 0.9 [48]. Indeed, for specific types of consumption, such as vehicle charging, the coefficients could be close to unity [49]. Therefore, a standard distribution network would not be able to cover the demand derived from a 100\% penetration of EVs with the current composition of the vehicle pool. In other words, considering a simultaneity coefficient close to 1.0 as feasible for the slow charging situation (dumb charging), the maximum penetration that EVs could reach is approximately $40 \%$. This value is similar to the results of other works using case studies with similar characteristics [24,50], providing values of penetration between $30 \%$ and $40 \%$.

To achieve higher penetration percentages, it would be necessary to change some of the parameters of the current mobility patterns. For example, the composition of the vehicle pool could evolve to different models, or the average daily mileage could decrease. However, based on the research data, not all the measures would be equally effective. For example, inducing a decrease in daily mileage from $55 \mathrm{~km} /$ day to $45 \mathrm{~km} /$ day (the lowest value in the reference range) with the same vehicle pool would have practically no effect on the penetration percentage, which would remain at around $40 \%$ due to the restrictive hypothesis of simultaneous charging. However, if the average mileage remained at $55 \mathrm{~km} /$ day, but the vehicle pool changed, the result would be very different. Table 5 provides a sensitivity analysis considering the sizes of the batteries (Table 2) with all vehicles included in the same category.

Table 5. Penetration percentages considering vehicle pool changes.

\begin{tabular}{cccccc}
\hline Electric Model & $\begin{array}{c}\text { Battery Range } \\
(\mathbf{k m})\end{array}$ & $\begin{array}{c}\text { Interval Between } \\
\text { Charging } \\
\text { (days) }\end{array}$ & $\begin{array}{c}\text { Maximum Power } \\
\text { Demand (kW) }\end{array}$ & $\begin{array}{c}\text { Minimum Power } \\
\text { Demand (kW) }\end{array}$ & $\begin{array}{c}\text { \% EV } \\
\text { Penetration }\end{array}$ \\
\hline Renault Twizy & 100 & 1.81 & 135 & 75 & 100 \\
Citroën C-Zero & 150 & 2.72 & 336 & 123 & 53 \\
Current Pool & & & 447 & 135 & 40 \\
Nissan Leaf & 200 & 3.63 & 531 & 146 & 33 \\
Volks. eGolf & 300 & 5.45 & 792 & 145 & 22 \\
Tesla Model 3 & 530 & 9.63 & 1782 & 185 & 10 \\
\hline
\end{tabular}

Thus, to reach higher EV penetration values, it is necessary for the current vehicle pool to transition to smaller models. For instance, if all the vehicles were those with the lowest engine power (a Renault Twizy or equivalent), the energy demand under slow charging would be below the capacity of all the MV/LV transformers. Even if one power step were to rise (Citroën C-Zero), the result would be $53 \%$ penetration. If we look at the current composition of the pool (Figure 4), the first objective might seem complicated, but the second appears relatively feasible given the concentration of vehicles in the second and third range of fiscal power. 


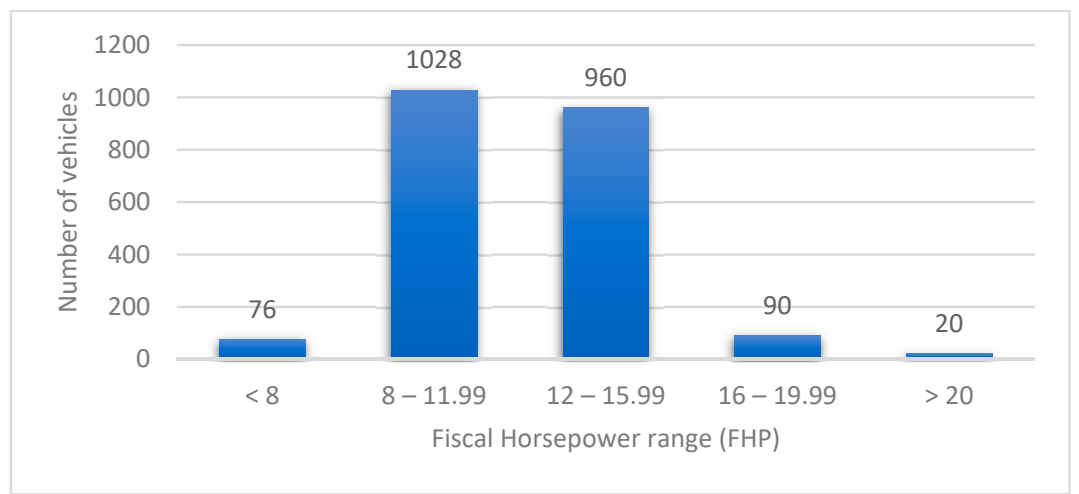

Figure 4. Vehicle pool composition according to fiscal power.

Although an increase in the size of batteries produces smaller simultaneity coefficients, the biggest vehicles have the poorest behavior from an electricity network capacity perspective because of their peak power demand, even in the optimum scenario, due to higher average energy consumption (Table 1). In order to quantify the profitability of using EVs instead of equivalent internal combustion engine vehicles (ICVs) for a given driving scenario, a comparative study is included (Figure 5). The results show that the TOCs of EVs could be lower than those for equivalent ICVs in each fiscal power group if charging is performed during off-peak hours. Only for the second range should the incentive of $29 \%$ the EV acquisition cost be considered due to its high difference in price compared to the equivalent ICVs with low mileage. Further details on this study can be found in Appendix B.

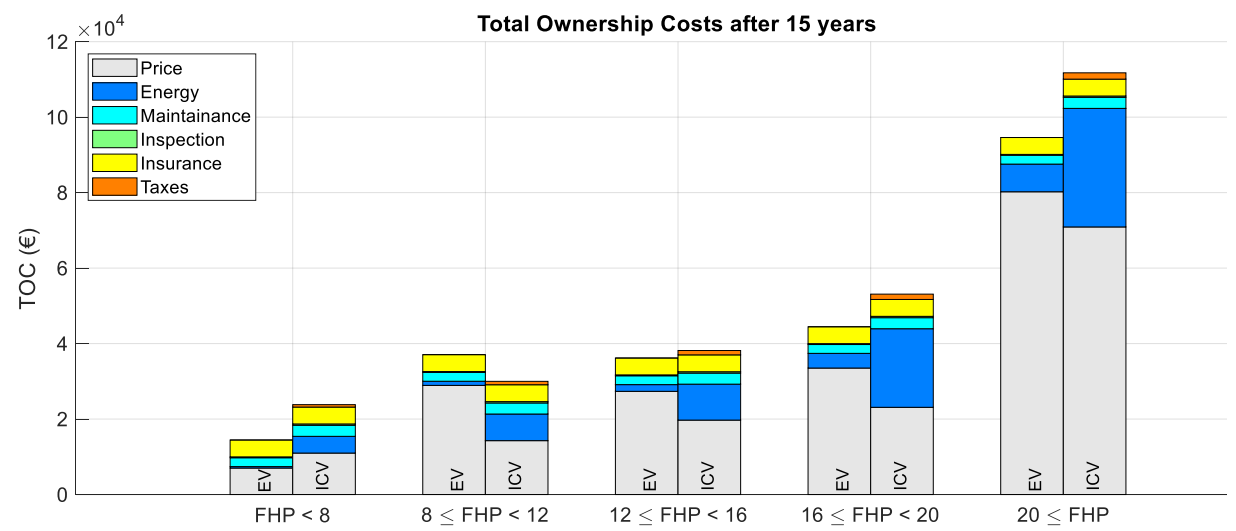

Figure 5. Disaggregated ownership costs of the electric vehicles (EVs) under study and the equivalent ICVs grouped by their fiscal power. The results refer to a time horizon of 15 years.

For these reasons, public policies should not only promote EVs as a friendly product with inherent advantages in air quality, urban noise, and environment impact, but should also promote more efficient vehicle models capable of decreasing overall energy demands under the existing infrastructure.

For fast and semi-fast charging, the results are much more accentuated Although the power demanded by these charging systems is excessive for domestic installations (which are usually between $5 \mathrm{~kW}$ and $10 \mathrm{~kW}$ ), without ignoring this issue, we focused on the MV/LV transformers' capacity as the foundation of the distribution network. The average power demand for semi-fast charging greatly exceeds the offer, even in the most favorable situation $(+42 \%)$, which makes this charging system unfeasible as a global solution for domestic purposes even when using intelligent charging systems [51]. For fast charging, the results show total infeasibility for users served from an LV line; thus, this charging technology is limited in practice to specific facilities for public supply [13]. Considering these issues, the methodology used to carry out this study would not be effective for analyzing the possibility to implement fast and semi-fast charging technologies in cities. 
The other method to increase EV penetration is by reinforcing the electrical grid. Two different scenarios were analyzed: i) an increase in the existing MV/LV transformers' capacity up to its maximum level; and ii) the construction of new MV/LV transformers with a standard capacity. According to e-distribución, the maximum capacity for a simple MV/LV is $1000 \mathrm{kVA}$, and $2000 \mathrm{kVA}$ for a double one. The results show that if the current MV/MV transformers were increased up to their maximum capacity and this increase was fully devoted to EV necessities (i.e., the rest of the LV loans remain stable), the new average power available during the night period would be around $679 \mathrm{~kW}$. Thus, the maximum average demand $(447 \mathrm{~kW})$ would be matched with a reinforcement of two-thirds of the $\mathrm{MV} / \mathrm{LV}$ transformers' capacity. In the second situation, new standard-capacity MV/LV transformers are built, which allows us to redistribute the same EV demand among more supply centers (the rest of the LV loans also remain equal). In this situation, three new MV/LV transformers would be necessary (each MV/LV transformer increases the EV penetration by $20 \%$ ) to meet the demand ( $25 \%$ over the existing transformers). The first situation is more feasible due to the difficulty of finding vacant lots to allocate new MV/LV transformers in consolidated cities. In addition, no further LV lines would be necessary. However, grid operators are usually reluctant to increase the MV/LV transformers' capacity up to the maximum level. From an economic point of view, both solutions are almost equivalent since the cost of the current MV/LV transformer reinforcements for each EV is $€ 58.88 /$ vehicle ( $€ 16.000$ for each $1000 \mathrm{kVA}$ transformer), and the cost per EV in the second situation would be around $€ 48.57 /$ vehicle ( $€ 35.20$ for each new $2 \times 630 \mathrm{MV} / \mathrm{LV}$ transformer). The latter should be increased alongside the LV line redistribution cost.

Although only the limitations of the electrical distribution network's capacity on the penetration of EVs were considered in this study, other aspects closely related to this public infrastructure might affect the large-scale commercialization of EVs. Apart from the topology of LV lines, which in many cases would have to be reinforced or expanded, the crucial limiting factor could be the lack of a fixed private parking allowing for slow charging over eight hours as a form of domestic consumption. In many cities as a whole or in particular areas within them (historical centers, over-densified areas, etc.), this lack of private parking could be the main limitation, due to electric infrastructure considerations $[52,53]$. This limitation is very difficult to overcome with public parking areas, since allowing a car to be parked in a public space for eight hours would be irrational from the perspective of mobility policy, which, in the long term, must be based on a solid commitment with public transport combined with a deterrent policy for private transport supported by a strong rotation of the few public spaces available for parking purposes [54]. However, even in these cases, EV penetration must be promoted, albeit with part of the demand fulfilled by public fast or semi-fast charging stations, possibly connected to a specific network.

\section{Conclusions}

This study has offered interesting results from two different perspectives. From a methodological point of view, the estimation at a micro level of both the electric network's capacity and the potential demand of a pool composed exclusively of EVs was very productive, allowing the simultaneous analysis of three charging situations under two different hypotheses. In this sense, the use of the municipal fiscal vehicle census was very effective for assessing not only the energy demand but also its concrete location. The applied methodology can thus be used in analyses of a similar nature, even in different physical or socioeconomic contexts.

From a substantive point of view, this study has shown that the capacity of a conventional electric distribution network can withstand up to $40 \%$ penetration of EVs under slow-charge conditions at night and an EV pool similar to the current ICE pool. Additionally, this work has highlighted the infeasibility of the implementation of domestic fast or semi-fast technologies for domestic purposes. This investigation has also shown that penetration percentages above $40 \%$ are difficult to obtain since the charging process is prone to simultaneity coefficients close to unity. Thus, the only way to improve the EV penetration averages using slow charge (where permitted by private parking availability) 
would be by changing the composition of the vehicle pool to lower power models. In this case, the study has shown that penetration values up to $55 \%$ or even higher could be reached. In addition, moderate MV/LV electric network reinforcements would allow the full penetration of EVs in our cities.

For all these reasons, the capacity of the electric distribution network would not be in the short or medium term an obstacle to public policies promoting electric mobility.

Author Contributions: Study conception and design: F.J.G.-J.; data collection: J.A.L.-S. and A.C.-G.; result analysis and interpretation: F.J.G.-J. and J.L.T.-M.; draft-manuscript preparation: F.J.G.-J. and J.L.T.-M. Supervision: A.G.-F. All authors reviewed the results and approved the final version of the manuscript.

Funding: This work was funded by the Spanish R + D + i Plan Project DPI2017-85007-R of the Ministry of Economy, Industry and Competitiveness and ERDF funds.

Acknowledgments: Almeria City Council; e-distribución.

Conflicts of Interest: There are no conflict of interest.

\section{Abbreviations}

$\begin{array}{ll}\text { EV } & \text { electric vehicle } \\ \text { FEV } & \text { fully electric vehicles } \\ \text { FHP } & \text { fiscal power } \\ \text { GHG } & \text { greenhouse gas } \\ \text { HEC } & \text { high electricity price charging } \\ \text { HEV } & \text { hybrid electric vehicles } \\ \text { ICE } & \text { internal combustion engine } \\ \text { ICV } & \text { internal combustion engine vehicle } \\ \text { LEC } & \text { low electricity price charging } \\ \text { LV } & \text { low voltage } \\ \text { MV/LV } & \text { medium voltage to low voltage } \\ \text { NEDC } & \text { new European driving cycle } \\ \text { TOC } & \text { total vehicle ownership costs } \\ \text { VAT } & \text { value-added tax } \\ \text { V2G } & \text { vehicle-to-grid } \\ \text { WHO } & \text { World Health Organization }\end{array}$

\section{Appendix A}

Table A1. Current vehicles for each fiscal range and MV/LV transformer.

\begin{tabular}{cccccc}
\hline MV/LV & \multicolumn{5}{c}{ Fiscal Power (FHP) } \\
Transformer Number & $<8$ & $\mathbf{8 - 1 1 . 9 9}$ & $\mathbf{1 2 - 1 5 . 9 9}$ & $\mathbf{1 6 - 1 9 . 9 9}$ & $>\mathbf{2 0}$ \\
\hline 103.385 & 2 & 65 & 60 & 6 & 0 \\
33.757 & 3 & 38 & 37 & 3 & 1 \\
102.743 & 0 & 5 & 4 & 1 & 0 \\
103.386 & 0 & 0 & 1 & 0 & 0 \\
34.312 & 16 & 166 & 116 & 10 & 5 \\
71.925 & 1 & 39 & 38 & 3 & 1 \\
33.766 & 12 & 100 & 97 & 9 & 2 \\
104.387 & 0 & 1 & 1 & 0 & 0 \\
33.850 & 5 & 93 & 79 & 6 & 2 \\
82.663 & 0 & 1 & 2 & 0 & 0 \\
33.855 & 15 & 195 & 212 & 18 & 3 \\
82.526 & 12 & 157 & 145 & 18 & 3 \\
33.765 & 4 & 46 & 65 & 8 & 1 \\
64.183 & 5 & 63 & 49 & 4 & 1 \\
91.791 & 0 & 20 & 21 & 1 & 1 \\
34.316 & 1 & 39 & 33 & 3 & 0 \\
TOTAL & 76 & 1028 & 960 & 90 & 20 \\
\hline
\end{tabular}




\section{Appendix B}

This appendix corresponds to a simulation analysis conducted to compare the TOCs of the vehicles considered in this work with respect to the equivalent ICVs in terms of power, size, and equipment. Moreover, the influence of the charging hour was addressed since two different electricity prices were considered, depending on the period of the day. The TOC was calculated as

$$
\operatorname{TOC}(n, d)=p+(e+b+m+s+i+t) \times \frac{1}{1+r} \times \frac{1-\left(\frac{1}{1+r}\right)^{n}}{1-\frac{1}{1+r}}
$$

where $n$ is the time horizon in years, $e$ is the energy cost per year, $p$ is the vehicle price, $m$ is the maintenance cost per year, $s$ is the technical inspection cost per year, $t$ is the tax cost per year, and $r$ is the discount rate.

For the simulation, the data represented in Table A2 were considered. Moreover, the following parameters, common for all the vehicles, were used: electricity costs of 0.1688 and $0.0737 € / \mathrm{kWh}$ during peak and off-peak hours, respectively [55]; a gasoline price of $1.1570 € / \mathrm{L}$; an average maintenance cost of $€ 182$ and $€ 228$ for electric and internal combustion engine vehicles, respectively, without considering the replacement of tires [56]; an average technical inspection cost of $€ 27.50$ per year, corresponding to nine inspections across the 15 years of the simulation for the ICV and $€ 18.00$ for the EV; an insurance cost of $€ 348$ per year; a tax cost between $€ 50$ and $€ 130$ per year, which is not applicable to the EVs, and a discount rate of $2 \%$. Thus, the annual energy costs for each EV were obtained as the product of the mileage. The specific consumption depicted in Table A2 increased by $25 \%$ based on the new European driving cycle (NEDC) specifications [56], a charging losses factor of 1.05 [56], and either the low or high electricity price mentioned before. Analogously, the energy cost of the ICVs was calculated as the product of mileage. The specific consumption depicted in Table A2 increased by $25 \%$ with respect to the NEDC specifications [55], with a gasoline price of $€ 1.1570 / L$. Finally, the value-added tax (VAT) in Spain is $21 \%$, which impacts the vehicle acquisition price and the electricity and gasoline prices of this simulation.

The results obtained for the simulation with a time horizon of 15 years are shown in Figures 5 and A1. Figure 5 shows the contribution of each of the terms included in Equation (A1) in a cumulative way. The TOC of each vehicle is presented by groups of FHP. In the first group, despite the low intensive use of the compared vehicles, the TOC of the electric vehicle is lower than that of the equivalent ICV. This is due mainly to its lower price, although the influence of the lower cost of energy consumption and (to a lesser extent) the lower maintenance cost and tax exemptions are also important. In the second group, the EV's TOC is higher than that of the equivalent ICV. This is mainly due to the high difference between their prices, which cannot be compensated with the rest of the costs due to the low annual mileage, which is mostly accrued under urban driving conditions. In order to make investment in EVs profitable, EV purchases should be incentivized by a discount of $29 \%$. In the third group, the TOCs are approximately the same. This is due to a lower difference in prices and higher annual mileage. In the fourth group, the EV is clearly the most economical alternative since the energy consumption cost drastically decreases as the annual mileage exceeds $20.000 \mathrm{~km}$. Finally, the same considerations are applicable to the fifth group, whose annual mileage exceeds $30.000 \mathrm{~km}$ and whose specific gasoline consumption is $0.074 \mathrm{~L} / \mathrm{km}$, resulting in a much lower EV TOC.

Table A2. Electric vehicles and their equivalent gasoline vehicles considered for the TOC analysis [42].

\begin{tabular}{|c|c|c|c|c|c|}
\hline \multirow{2}{*}{$\begin{array}{l}\text { Fiscal Power } \\
\text { (FHP) }\end{array}$} & \multirow[b]{2}{*}{ Vehicle Model } & \multicolumn{2}{|c|}{ Consumption } & \multirow{2}{*}{$\begin{array}{l}\text { Distance } \\
(\mathrm{km} / \text { year) }\end{array}$} & \multirow[b]{2}{*}{ Price $(€)$} \\
\hline & & $\begin{array}{l}\text { Electricity } \\
(\mathrm{kWh} / \mathrm{km})\end{array}$ & $\begin{array}{l}\text { Gasoline } \\
(\mathrm{L} / \mathbf{k m})\end{array}$ & & \\
\hline \multirow{2}{*}{$<8$} & Renault Twizy Life 45 & 0.06 & - & 3650 & 5800 \\
\hline & Aixam City Pack & - & 0.031 & 3650 & 9082 \\
\hline \multirow{2}{*}{ 8-11.99 } & Citroen C-Zero & 0.10 & - & 7300 & 23.900 \\
\hline & Citroen C1 1.2 VTI & - & 0.054 & 7300 & 11.800 \\
\hline \multirow{2}{*}{$12-15.99$} & Nissan LEAF & 0.12 & - & 9855 & 22.600 \\
\hline & Nissan Micra & - & 0.050 & 9855 & 16.300 \\
\hline \multirow{2}{*}{ 16-19.99 } & Volkswagen eGolf & 0.12 & - & 21.535 & 27.700 \\
\hline & Volkswagen Sportsvan 1.5 TSI & - & 0.051 & 21.535 & 19.100 \\
\hline \multirow{2}{*}{$>20$} & Tesla Model 380.5 kWh & 0.15 & - & 32.485 & 66.300 \\
\hline & BMW 340i xDrive G21 & - & 0.074 & 32.485 & 58.600 \\
\hline
\end{tabular}

Figure A1 shows the annual TOCs of the compared vehicles throughout the analyzed period of 15 years. In this case, the TOCs corresponding to peak hour charging are included. Figure A1a shows that the TOCs of the EVs of the first group remains lowest during the entire simulation. Analogously, Figure A1b shows that the TOCs of the ICVs of the second group remains lower at each moment. However, Figure A1c show that the TOCs of the EVs of the third group become lower than the TOCs of the ICVs after year 11 for low electricity price charging (LEC), whereas the TOCs of the EVs under high electricity price charging (HEC) remain higher during the entire simulation. For the fourth group, Figure A1d shows that the EV TOC becomes lower than the TOC of the ICV 
in years 8 and 11 for LEC and HEC, respectively. The same occurs in years 5 and 8 for group 5, as depicted in Figure A1e. The reductions in the cost of energy consumption between LEC and HEC by group are $€ 496, € 1417$, $€ 2296$, €5018, and $€ 9462$, respectively, which highlights the importance of charging the vehicles during the periods of the day when the price of the electricity is lower (usually night).
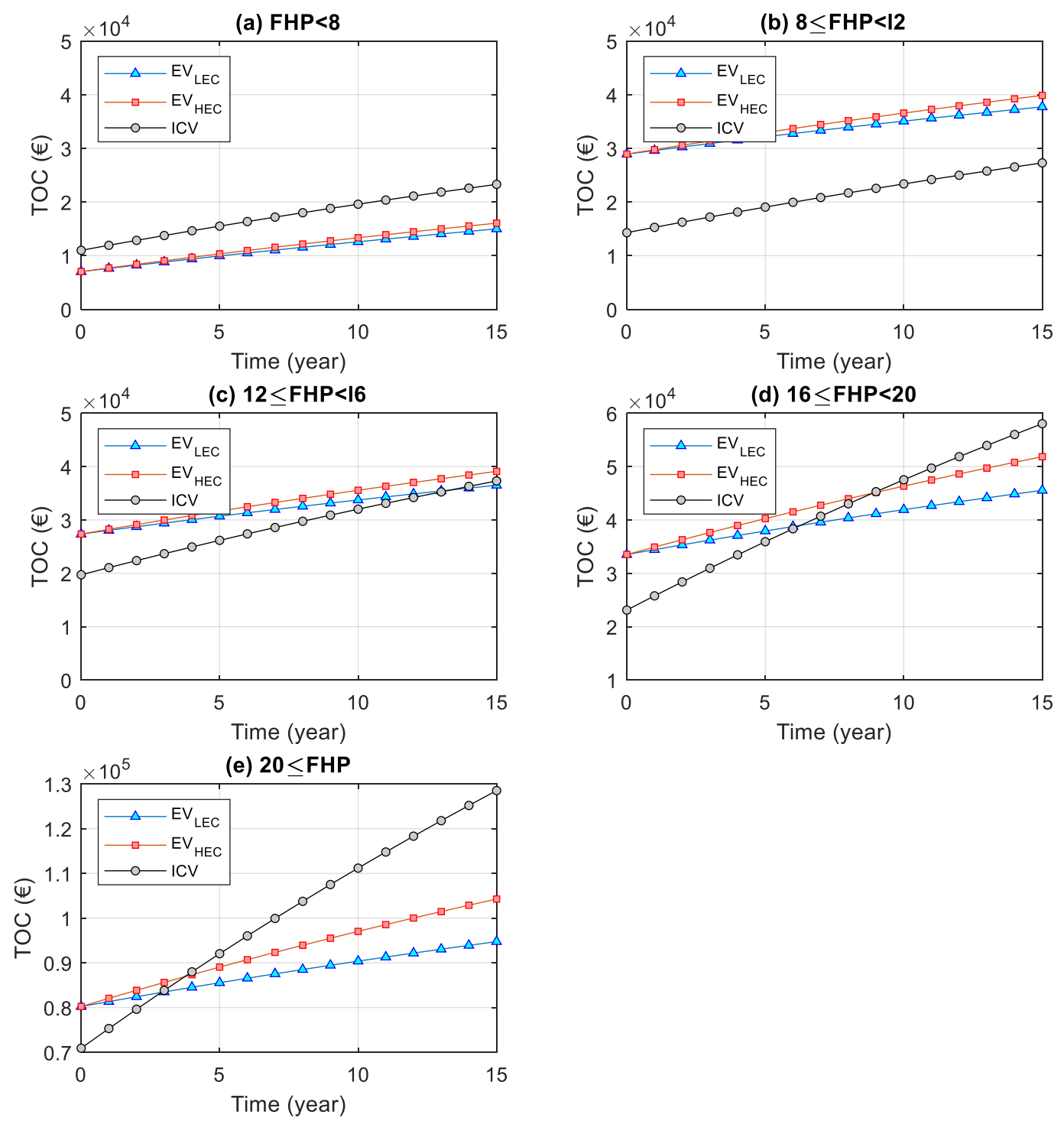

Figure A1. The annual TOCs of the analyzed vehicles by group. The blue and red lines correspond to the TOCs of the EVs with low and high electricity price charging, respectively. The black line represents the TOCs of the equivalent ICVs; (a) annual TOCs of the vehicles of the first range of fiscal power; (b) annual TOCs of the vehicles in the second range of fiscal power; (c) annual TOCs of the vehicles of the third range of fiscal power; (d) annual TOCs of the vehicles of the fourth range of fiscal power; (e) annual TOCs of the vehicles of the fifth range of fiscal power.

\section{References}

1. Cohen, A.J.; Anderson, H.R.; Ostro, B.; Pandey, K.D.; Krzyzanowski, M.; Künzli, N.; Gutschmidt, K.; Pope, A.; Romieu, I.; Samet, J.M.; et al. The global burden of disease due to outdoor air pollution. J. Toxicol. Environ. Heal. Part A 2005, 68, 1301-1307. [CrossRef] [PubMed]

2. Brauer, M.; Amann, M.; Burnett, R.T.; Cohen, A.; Dentener, F.; Ezzati, M.; Henderson, S.B.; Krzyzanowski, M.; Martin, R.V.; Van Dingenen, R.; et al. Exposure Assessment for Estimation of the Global Burden of Disease Attributable to Outdoor Air Pollution. Environ. Sci. Technol. 2011, 46, 652-660. [CrossRef] [PubMed] 
3. Liu, Y.; Sun, J.; Gou, Y.; Sun, X.; Zhang, D.; Xue, F. Analysis of Short-Term Effects of Air Pollution on Cardiovascular Disease Using Bayesian Spatio-Temporal Models. Int. J. Environ. Res. Public Health 2020, $17,879$. [CrossRef] [PubMed]

4. Van Fan, Y.; Perry, S.; Klemeš, J.J.; Lee, C.T. A review on air emissions assessment: Transportation. J. Clean. Prod. 2018, 194, 673-684. [CrossRef]

5. Reznik, A.; Kissinger, M.; Alfasi, N. Real-data-based high-resolution GHG emissions accounting of urban residents private transportation. Int. J. Sustain. Transp. 2019, 13, 235-244. [CrossRef]

6. Lin, Z.; Greene, D.L. Promoting the market for plug-in hybrid and battery electric vehicles. Transp. Res. Rec. 2011, 2252, 49-56. [CrossRef]

7. Statharas, S.; Moysoglou, Y.; Siskos, P.; Zazias, G.; Capros, P. Factors influencing electric vehicle penetration in the EU by 2030: A model-based policy assessment. Energies 2019, 12, 2739. [CrossRef]

8. Struben, J.; Sterman, J.D. Transition challenges for alternative fuel vehicle and transportation systems. Environ. Plan. B Plan. Des. 2008, 35, 1070-1097. [CrossRef]

9. Hübner, Y.; Blythe, P.; Hill, G.; Neaimeh, M.; Austin, J.; Gray, L.; Herron, C.; Wardle, J. 49 ,999 electric car journeys and counting. In Proceedings of the 2013 World Electric Vehicle Symposium and Exhibition, EVS 2014, Barcelona, Spain, 17-20 November 2013; Institute of Electrical and Electronics Engineers Inc.: Piscataway, NJ, USA, 2014.

10. Rahmani, D.; Loureiro, M.L. Assessing drivers' preferences for hybrid electric vehicles (HEV) in Spain. Res. Transp. Econ. 2019, 73, 89-97. [CrossRef]

11. Jensen, A.F.; Rasmussen, T.K.; Prato, C.G. A Route Choice Model for Capturing Driver Preferences When Driving Electric and Conventional Vehicles. Sustainability 2020, 12, 1149. [CrossRef]

12. Torres, J.L.; Gonzalez, R.; Gimenez, A.; Lopez, J. Energy management strategy for plug-in hybrid electric vehicles. A comparative study. Appl. Energy 2014, 113, 816-824. [CrossRef]

13. Martínez-Lao, J.; Montoya, F.G.; Montoya, M.G.; Manzano-Agugliaro, F. Electric vehicles in Spain: An overview of charging systems. Renew. Sustain. Energy Rev. 2017, 77, 970-983. [CrossRef]

14. Propfe, B.; Redelbach, M.; Santini, D.; Friedrich, H. Cost analysis of Plug-in Hybrid Electric Vehicles including Maintenance \& Repair Costs and Resale Values. World Electr. Veh. J. 2012, 5, 886-895.

15. Montoya, F.G.; Martínez-Lao, J.; Torres-Moreno, J.; Manzano-Agugliaro, F.; Barón, V. Analysis of charging stations for electric vehicles in Spain. Renew. Energy Power Qual. J. 2016, 6, 7.

16. Torres-Moreno, J.L.; Gimenez-Fernandez, A.; Perez-Garcia, M.; Rodriguez, F. Energy management strategy for micro-grids with PV-battery systems and electric vehicles. Energies 2018, 11, 522. [CrossRef]

17. Ul-Haq, A.; Cecati, C.; Strunz, K.; Abbasi, E. Impact of Electric Vehicle Charging on Voltage Unbalance in an Urban Distribution Network. Intell. Ind. Syst. 2015, 1, 51-60. [CrossRef]

18. Spitzer, M.; Schlund, J.; Apostolaki-Iosifidou, E.; Pruckner, M. Optimized integration of electric vehicles in low voltage distribution grids. Energies 2019, 12, 4059. [CrossRef]

19. Nour, M.; Ali, A.; Farkas, C. Evaluation of Electric Vehicles Charging Impacts on a Real Low Voltage Grid. Int. J. Power Eng. Energy 2018, 9, 837-842.

20. Ramadan, H.; Ali, A.; Farkas, C. Assessment of plug-in electric vehicles charging impacts on residential low voltage distribution grid in Hungary. In Proceedings of the 2018 6th International Istanbul Smart Grids and Cities Congress and Fair, ICSG 2018, Istanbul, Turkey, 25-26 April 2018; Institute of Electrical and Electronics Engineers Inc.: Piscataway, NJ, USA, 2018; pp. 105-109.

21. Richardson, P.; Moran, M.; Taylor, J.; Maitra, A.; Keane, A. Impact of electric vehicle charging on residential distribution networks: An Irish demonstration initiative. In Proceedings of the 22nd International Conference and Exhibition on Electricity Distribution (CIRED 2013), Stockholm, Sweden, 10-13 June 2013; pp. 10-13.

22. Tie, C.H.; Gan, C.K.; Ibrahim, K.A. The impact of electric vehicle charging on a residential low voltage distribution network in Malaysia. In Proceedings of the 2014 IEEE Innovative Smart Grid Technologies-Asia, ISGT ASIA 2014, Kuala Lumpur, Malaysia, 20-23 May 2014; IEEE Computer Society: Washington, DC, USA, 2014; pp. 272-277.

23. Richardson, P.; Flynn, D.; Keane, A. Optimal charging of electric vehicles in low-voltage distribution systems. IEEE Trans. Power Syst. 2012, 27, 268-279. [CrossRef]

24. Richardson, P.; Flynn, D.; Keane, A. Impact assessment of varying penetrations of electric vehicles on low voltage distribution systems. In Proceedings of the IEEE PES General Meeting, PES 2010, Providence, RI, USA, 25-29 July 2010. 
25. Arellano, B.; Sena, S.; Abdollahy, S.; Lavrova, O.; Stratton, S.; Hawkins, J. Analysis of electric vehicle impacts in New Mexico urban utility distribution infrastructure. In Proceedings of the 2013 IEEE Transportation Electrification Conference and Expo (ITEC), Detroit, MI, USA, 16-19 June 2013; pp. 1-6.

26. Hatziargyriou, N.; Karfopoulos, E.L.; Tsatsakis, K. The impact of EV charging on the system demand. In Electric Vehicle Integration into Modern Power Networks; Springer: New York, NY, USA, 2013; pp. 57-85. ISBN 9781461401346.

27. Saisirirat, P.; Chollacoop, N.; Tongroon, M.; Laoonual, Y.; Pongthanaisawan, J. Scenario analysis of electric vehicle technology penetration in Thailand: Comparisons of required electricity with power development plan and projections of fossil fuel and greenhouse gas reduction. Energy Procedia 2013, 34, 459-470. [CrossRef]

28. Lopes, J.A.P.; Soares, F.J.; Almeida, P.M.R. Integration of electric vehicles in the electric power system. Proc. IEEE 2011, 99, 168-183. [CrossRef]

29. Luo, X.; Chan, K.W. Real-time scheduling of electric vehicles charging in low-voltage residential distribution systems to minimise power losses and improve voltage profile. IET Gener. Transm. Distrib. 2014, 8, 516-529. [CrossRef]

30. Lacey, G.; Putrus, G.; Bentley, E.; Johnston, D.; Walker, S.; Jiang, T. A modelling tool to investigate the effect of electric vehicle charging on low voltage networks. In Proceedings of the 2013 World Electric Vehicle Symposium and Exhibition, EVS 2014, Barcelona, Spain, 17-20 November 2013; Institute of Electrical and Electronics Engineers Inc.: Piscataway, NJ, USA, 2014.

31. Mateo, C.; Frías, P.; Sánchez-Miralles, A. Distribution planning with hourly profiles for analysing electric vehicle charging strategies. Int. J. Electr. Hybrid Veh. 2016, 8, 1-18. [CrossRef]

32. Hong, J.; Xiang, Y.; Liu, Y.; Liu, J.; Li, R.; Li, F.; Gou, J. Development of EV charging templates: An improved K-prototypes method. IET Gener. Transm. Distrib. 2018, 12, 4361-4367. [CrossRef]

33. Schäuble, J.; Kaschub, T.; Ensslen, A.; Jochem, P.; Fichtner, W. Generating electric vehicle load profiles from empirical data of three EV fleets in Southwest Germany. J. Clean. Prod. 2017, 150, 253-266. [CrossRef]

34. Draz, M.; Albayrak, S. A Power Demand Estimator for Electric Vehicle Charging Infrastructure. In Proceedings of the 2019 IEEE Milan PowerTech, Milan, Italy, 23-27 June 2019; pp. 1-6.

35. Frías Marín, P.; Mateo Domingo, C.; Pérez Arriaga, J. Evaluación del impacto de la integración del coche eléctrico en las redes de distribución de energía eléctrica. Lychnos 2011, 6, 56-61.

36. Putrus, G.A.; Suwanapingkarl, P.; Johnston, D.; Bentley, E.C.; Narayana, M. Impact of electric vehicles on power distribution networks. In Proceedings of the 5th IEEE Vehicle Power and Propulsion Conference, VPPC '09, Dearborn, MI, USA, 7-10 September 2009; pp. 827-831.

37. Dyke, K.J.; Schofield, N.; Barnes, M. The impact of transport electrification on electrical networks. IEEE Trans. Ind. Electron. 2010, 57, 3917-3926. [CrossRef]

38. Papadopoulos, P.; Skarvelis-Kazakos, S.; Grau, I.; Cipcigan, L.M.; Jenkins, N. Predicting electric vehicle impacts on residential distribution networks with distributed generation. In Proceedings of the 2010 IEEE Vehicle Power and Propulsion Conference, VPPC 2010, Lille, France, 1-3 September 2010.

39. Olivella-Rosell, P.; Villafafila-Robles, R.; Sumper, A.; Bergas-Jané, J. Probabilistic Agent-Based Model of Electric Vehicle Charging Demand to Analyse the Impact on Distribution Networks. Energies 2015, 8, 4160-4187. [CrossRef]

40. Red-Eléctrica-de-España. REE Web Site. Available online: https://www.ree.es/en (accessed on 26 March 2020).

41. Senabre, C.; Valero, S.; Gabaldón, A.; Ortiz, M.; González, M. Predicción de la Demanda Total de Energía Eléctrica Española Utilizando Mapas Auto-organizados como Modelo de Red Neuronal. In Proceedings of the International Conference on Modern Eléctrical Power Engineering, Zaragoza, Spain, 2-4 July 2009; pp. 2-7.

42. Ministerio-de-Hacienda Orden HAC/1273/2019. Available online: https://www.boe.es/eli/es/o/2019/12/16/ hac1273 (accessed on 4 May 2020).

43. Golob, T.F.; Gould, J. Projecting use of electric vehicles from household vehicle trials. Transp. Res. Part B Methodol. 1998, 32, 441-454. [CrossRef]

44. Pearre, N.S.; Kempton, W.; Guensler, R.L.; Elango, V.V. Electric vehicles: How much range is required for a day's driving? Transp. Res. Part C Emerg. Technol. 2011, 19, 1171-1184. [CrossRef]

45. Franke, T.; Krems, J.F. What drives range preferences in electric vehicle users? Transp. Policy 2013, 30, 56-62. [CrossRef] 
46. Rusck, S. The Simultaneous Demand in Distribution Networks Supplying Domestic Consumers. ASEA J. 1956, 10, 59-61.

47. Gwisdorf, B.; Stepanescu, S.; Rehtanz, C. Effects of demand side management on the planning and operation of distribution grids. In Proceedings of the IEEE PES Innovative Smart Grid Technologies Conference Europe, ISGT Europe, Gothenberg, Sweden, 11-13 October 2010.

48. De Groot, R.J.W.; Morren, J.; Slootweg, J.G. Investigation of simultaneity in distribution networks for the assessment of da feasibility. In Proceedings of the 2012 47th International Universities Power Engineering Conference (UPEC), London, UK, 4-7 September 2012; pp. 1-6.

49. Protopapadaki, C.; Saelens, D. Heat pump and PV impact on residential low-voltage distribution grids as a function of building and district properties. Appl. Energy 2017, 192, 268-281. [CrossRef]

50. Clement-Nyns, K.; Haesen, E.; Driesen, J. The Impact of Charging Plug-In Hybrid Electric Vehicles on a Residential Distribution Grid. IEEE Trans. Power Syst. 2010, 25, 371-380. [CrossRef]

51. Kordkheili, R.A.; Bak-Jensen, B.; Pillai, J.R.; Bhattarai, B.P. Improving and handling electric vehicle penetration level by different smart charging algorithms in distribution grids. In Proceedings of the 2015 IEEE Eindhoven PowerTech, Eindhoven, The Netherlands, 29 June-2 July 2015; Institute of Electrical and Electronics Engineers Inc.: Piscataway, NJ, USA, 2015.

52. Poblet, M. Los aparcamientos residenciales, privados y municipales, en el contexto del mercado inmobiliario: Estudio económico y financiero de los precios de la ciudad de Barcelona. Ciudad y Territ. Estud. Territ. 2002, 132, 345-360.

53. Marsden, G. The evidence base for parking policies-a review. Transp. Policy 2006, 13, 447-457. [CrossRef]

54. Pozueta, J. Movilidad y Planeamiento Sostenible: Hacia una Consideración Inteligente del Transporte y la Movilidad en el Planeamiento y en el Diseño Urbano; Cuadernos de investigación urbanística; Instituto Juan de Herrera: Madrid, Spain, 2000; ISBN 9788495365361.

55. Ramos-Teodoro, J.; Rodríguez, F.; Berenguel, M.; Torres, J.L. Heterogeneous resource management in energy hubs with self-consumption: Contributions and application example. Appl. Energy 2018, 229, 537-550. [CrossRef]

56. Wirges, J. Planning the Charging Infrastructure for Electric Vehicles in Cities and Regions; KIT Scientific Publishing: Karlsruhe, Germany, 2016. 